Keywords: digital marketing; symbolic positioning; soft power; communication; digital diplomacy; power; image; brand

\title{
REFERENCES
}

Ankhol't, S. and Khil'dret, D. (2010) Brend Amerika: mat' vsekb brendov. Moscow, Izd-vo «Dobraia kniga». 232 p. (In Russ.).

Nye, J. (2011a) Soft power. N. Y., Public Affairs. 130 p.

Nye, J. (2011b) The future of power. N. Y., Public Affairs. 320 p.

Rosendorf, N. M. (2000) Social and Cultural Globalization. Maastricht University, Wash. 123 p.

Submission date: 02.06.2019.

Мухаев Рашид Тазитдинович - доктор политических наук, профессор, профессор кафедры теории рекламы и массовых коммуникаций Московского гуманитарного университета. Адрес: 111395, Россия, г. Москва, ул. Юности, д. 5, корп. 3. Тел.: +7 (499) 374-78-45. Эл. адрес: muhaev_r@mail.ru

Mukhaev Rashid Tazitdinovich, Doctor of Political Science, Professor, Professor, Department of Theory of Advertising and Mass Communication, Moscow University for the Humanities. Postal address: 5, Yunosti St., Moscow, Russian Federation, 111395. Tel.: +7 (499) 374-78-45. E-mail: muhaev_r@mail.ru

DOI: $10.17805 / z p u .2019 .4 .16$

\section{Патриотическая направленность массовых праздников современной России и молодежь}

\author{
Г. П. ХОРИНА, Д. А. СТРЕЛЬЦОВА \\ МОСКОВСКИЙ ГУМАНИТАРНЫЙ УНИВЕРСИТЕТ
}

В статье анализируется проблема патриотической направленности современных массовых праздников и ее восприятие российской молодежью.

Отмечается, что перемены, произошедшие в общественном развитии России, привели к изменению у части молодежи отношения к своей стране, ее истории. Государство, к сожалению, не уделяет достаточного внимания молодежи. В поисках реализации себя молодые люди часто подпадают под влияние людей с антироссийской, антипатриотической направленностью. Чтобы не допустить этого, необходимо использовать различные формы воспитательного воздействия. Немалую роль могут сыграть здесь многочисленные событийные мероприятия и праздники патриотической направленности.

Ключевые слова: праздник; массовый праздник; патриотизм; патриотическое воспитание; Россия; День Победы; День России; День государственного флага; День народного единства

\section{ВВЕАЕНИЕ}

Соременное молодое поколение России живет в условиях, отличающихся от тех, в которых определенное время жили их родители. Изменился общественный строй, появились другие ценности, идеалы, идеи. У части молодых людей изменилось отношение к своей стране, ее истории, современной ситуации. Отсутствие необходи- 
мых достоверных знаний об особенностях исторического развития нашего государства, отрицание традиционных ценностей, непонимание процессов, которые происходят в обществе сегодня, являются благодатной почвой для вовлечения их в различные объединения, группы с антироссийской, антипатриотической направленностью. Чтобы не допустить этого, используются различные формы воспитательного воздействия. К ним относятся и праздники, зарекомендовавшие себя эффективным средством патриотического воспитания как зрелище бесплатное и доступное.

Прежде чем приступить к анализу современных массовых праздников как формы патриотического воспитания, определимся с рабочими для нас понятиями «праздник» и «массовый праздник». Согласно энциклопедии «Культурология. XX век», праздник - это «противопоставленный будням (повседневности) отрезок времени, характеризующийся радостью и торжеством, выделенный в потоке времени в память или в честь кого или чего-либо, обладающий сущностной связью со сферой сакрального, отмечаемый в культурной или религиозной традиции как институционализированное действо, которое обеспечивает его участникам максимальную причастность к этой сфере. Цель Праздника - не только достижение определенного оптимального душевного состояния участвующих в нем людей, но и восстановление определенного среднего уровня этого состояния, сниженного различными ситуациями, которые квалифицируются как отрицательные» (Культурология. ХХ век, 1998: 134).

Массовый праздник, по мнению российского исследователя А. М. Генкина, представляет собой «явление необычное, синтезирующее действительность и искусство, художественно оформляющее то или иное реальное жизненное событие» (Генкин, 1975: 79).

Формирование чувства патриотизма, гордости и уважения к своему Отечеству, усвоение системы ценностей, духовных ориентиров начинается, как известно, у детей с раннего возраста. Аля патриотизма характерными чертами являются ответственность перед страной, привязанность к семье, к домашнему очагу, родной земле, ее природе, толерантность к людям разных национальностей. Эти качества формируются в процессе патриотического воспитания, направленного на усвоение культурных ценностей, развитие уважительного отношения к своему государству. Немалую роль играет проведение многочисленных событийных мероприятий и праздников патриотической направленности. Как правильно отмечал А. М. Генкин, «любое торжество, имеющее общественное звучание, сплачивает людей, утверждает высокие патриотические чувства» (там же: 62).

Анализ любой российской программы по патриотическому воспитанию показывает, что в каждой отведено определенное место организации и проведению таких мероприятий и праздников, посвященных Великой Победе, защитнику Отечества, Аню народного единства, Государственному флагу, различным родам войск, а также юбилейным датам выдающихся людей и т. д.

\section{ПРАЗАНИКИ ПАТРИОТИЧЕСКОЙ НАПРАВАЕННОСТИ В СОВРЕМЕННОЙ РОССИИ}

В современной России всплеск патриотизма особо проявился во время Олимпийских и Паралимпийских игр 2014 г., а также в связи с историческим событием воссоединением Крыма с Россией в этом же году. Здесь уместно вспомнить, что в советское время на территории Крыма находился известный всему миру пионерский лагерь «Артек», основанный в 1925 г. и просуществовавший до 1991 г. Он имел богатейшую 
историю, в том числе проведения массовых патриотических праздников. Среди них можно назвать такие массовые праздники и международные фестивали, как «Салют, Победа!» (1975 г.), посвященный 30-летию Победы, Первый Международный фестиваль «Пусть всегда будет солнце» (1977 г.), Международный фестиваль «За счастливое детство в мирном мире» (1979 г.), на котором присутствовал посетивший «Артек» генеральный секретарь ЦК КПСС $\Lambda$. И. Брежнев, детскую программу Всемирного фестиваля молодежи и студентов, проходившего не только на площадках Москвы, но и в «Артеке» (1985 г.), Международные фестивали культуры и спорта (1989-1990 гг.). Организаторы этих праздников пытались донести до их участников идеи, которые в общедоступной форме пропагандировали мир и дружбу между народами не только советских республик, но и зарубежных стран.

Поэтому представляется чрезвычайно важной и своевременной идея возрождения массовых праздников как формы патриотического воспитания на его территории. Международный центр «Артек» обретает новую жизнь, становится главной площадкой для проведения массовых праздников детей и юношества не только из разных регионов Российской Федерации, но и стран ближнего и дальнего зарубежья. Он продолжает славные традиции когда-то главного пионерского лагеря страны. Проекты «Артека» направлены на развитие чувства патриотизма, навыков толерантного взаимодействия между детьми разных национальностей. Этому способствуют массовые праздники, во время которых происходит не только обмен опытом использования культурного наследия своей страны, но и демонстрация его в различных формах.

Одним из недавно реализованных проектов стал праздник детского и юношеского творчества «Всегда должны смеяться дети и в мирном мире жить!», организованный в «Артеке» в сентябре 2016 г. Основная идея праздника состояла в том, чтобы дети и юношество - представители различных культур народов и стран, их духовного наследия (традиций, обычаев, обрядов, фольклора, песенной и танцевальной культуры) смогли поделиться своим наследием друг с другом. Существенной составляющей праздника стали программы, конкурсы, встречи, которые позволили молодым людям показать самобытность и достижения своих культур, помогли увидеть и понять, что у молодежи разных стран похожие проблемы, целевые установки и ценностные ориентации, что молодые связывают свою судьбу и судьбу своих стран с устойчивым развитием и процветанием. В программе праздника широко использовались «национальные гостиные», на которых в интерактивной форме показывались достижения культуры своего народа, проходили дни национальных культур и национальных кухонь, мастер-классы выдающихся представителей культуры и искусства, руководителей творческих коллективов праздника, а также творческие встречи с художественными коллективами Крыма и кульминация праздника - гала-концерт. Подобное межкультурное взаимодействие стало тем эффективным коммуникационным пространством, которое способствовало не только формированию художественно-эстетического вкуса, но прежде всего воспитанию патриотизма у подрастающего поколения.

Заметим, что праздник детского и юношеского творчества «Всегда должны смеяться дети и в мирном мире жить!» как культурно-образовательный и патриотическивоспитательный проект детей и юношества получил высокую оценку и признание широкой педагогической и творческой общественности, стал заметным событием в системе образовательной деятельности Международного центра «Артек». Авторский 


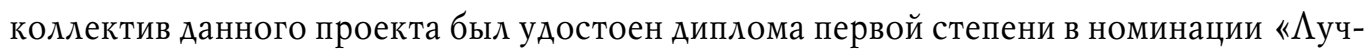
шее представление для детей и юношества», Всероссийской премии «Грани театра масс» за достижения в области массовых форм искусства.

\section{ГОСУААРСТВЕННЫЕ ПРАЗАНИКИ СОВРЕМЕННОЙ РОССИИ}

Тема патриотического воспитания является сегодня важным әлементом государственной политики как на федеральном, так и на региональном уровнях. В. В. Путин в своих выступлениях неоднократно акцентировал внимание на основополагающих смыслах патриотизма и патриотического воспитания для обеспечения благоприятного развития нашего государства и общества. Он заявлял, что будущее нашей страны должно основываться на прочном фундаменте патриотизма. Без сохранения российской идентичности и культивирования чувства патриотизма наше Отечество не будет существовать, оно просто развалится изнутри ${ }^{1}$. По нашему мнению, жизнеспособность государства, общества и будущее нашей страны непосредственно зависят от воспитания патриотически настроенной молодежи.

История современных государственных праздников России берет свое начало с 2000-х гг., со времени их утверждения. За прошедшие почти 20 лет праздники стали важным элементом культуры повседневности. Основные государственные праздники носят массовый характер, они служат для повышения национального самосознания, воспитания патриотизма, привития лояльности к своей стране. Можно предположить, что проведение таких патриотических мероприятий не оставит молодое поколение равнодушным. Число молодых людей, желающих принять активное участие в их организации и проведении, постоянно возрастает, делают они это с удовольствием, и это оказывает влияние на воспитание чувства патриотизма.

Проанализируем наиболее важные государственные праздники современной России с точки зрения их патриотической направленности.

В России одним из самых почитаемых и радостных праздников «со слезами на глазах» является 9 мая - Аень великой Победы Советского Союза над фашистской Германией в годы Великой Отечественной войны. В этот важный для нашей страны день основная масса людей отдает дань уважения памяти павших героев, проходит чествование ныне здравствующих ветеранов войны. На площадях, в метро звучат патриотические песни, устраиваются различные праздничные шоу.

Ярким событием этого дня стала Всероссийская акция «Бессмертный полк», которая впервые в современном формате состоялась 9 мая 2012 г. в Томске, когда молодые люди прошли цепочкой с фотографиями участников войны к Вечному огню. Эта акция за несколько лет превратилась во всенародное движение, получила широкое распространение по всей стране, число желающих участвовать в ней с каждым годом увеличивается. Она также нашла поддержку во многих странах мира. Конечно, значимость этой акции не в численности принявших в ней участие, а в том единении духа, искренности и признательности тем, кто, рискуя собственной жизнью, отстоял свободу и независимость не только нашей Родины, но и народов многих стран. Одной из главных задач акции, как записано в ее уставе ${ }^{2}$, является сохранение памяти в каждой семье об участниках Великой Отечественной войны. Акция становится замечательной традицией, которая объединила многих, и особенно важна она для современной молодежи.

Еще одна из крупномасштабных всероссийских акций патриотической направленности - «Георгиевская ленточка» - впервые была проведена с 25 апреля по 9 мая 
2005 г., в год 60-летия Победы. Она также стала одним из самых заметных событий, посвященных Аню Победы. Появилась акция стихийно, став продолжением образовательного историко-патриотического проекта «Наша Победа». Теперь, когда все меньше становится среди нас ветеранов Великой Отечественной войны, необходимо, чтобы этот праздник не превратился в формальный акт, а также не потерялась его «душевная составляющая».

Одним из новых государственных праздников является Аень России, который отмечается с 12 июня 1990 г. - с момента принятия I Съездом народных депутатов РСФСР Аекларации о государственном суверенитете. Заметим, что многие соотечественники все больше воспринимают его как возможность насладиться первыми летними днями, провести их за городом. Между тем без серьезной государственной поддержки, и в первую очередь идеологической, направленной на повседневное воспитание, этот праздник обречен остаться еще одним днем в формате «выходной+», когда бонусом к дополнительному уикенду будут концерты, фейерверки и шоу «кто-во-чтогоразд». Чтобы этот праздник все больше и больше находил поддержку, у россиян главным для массовых мероприятий не должен быть зашкаливающий градус пафосности и развлекательности, а его содержательная составляющая.

Как известно, 22 августа в России отмечается Аень Государственного флага Российской Федерации. Впервые триколор в качестве государственного флага был поднят в 1991 г. Аля Российской Федерации это сравнительно молодой праздник, и пока формальный. Несмотря на тот факт, что празднику уже 20 лет, в России он широко не празднуется - отмечается отдельными акциями и мероприятиями, чаще всего инициированными «сверху». Аля российского молодого человека, как, впрочем, и для большинства людей, день государственного триколора часто проходит незамеченным. $\mathrm{O}_{\mathrm{A}}$ нако потенциал у этого праздника большой. Успешной его реализации мешает отсутствие единой четко продуманной государственной политики в сфере формирования национального самосознания и патриотизма. Празднование отдается на откуп местным властям, те часто занимаются им по остаточному принципу, экономя средства и силы. В то же время при желании можно найти множество простых, но эффектных решений для того, чтобы этот праздник в российских городах прошел на высоком уровне. К сожалению, сегодня он не имеет собственной четко выраженной идентичности. Призванный нести основательную идеологическую нагрузку, он зачастую не справляются с этой задачей. Это легко объясняется его относительной «молодостью»- у него за плечами нет многовековой истории. Возможно, со временем он, как и другие новые праздники, станет для народа не просто лишним поводом для отдыха и веселья, а символом российской государственности, но для этого им необходимо обрести «собственное лицо». Этому должны способствовать и общая государственная политика в сфере патриотического воспитания граждан, и популяризация их центральных идей, и введение ярких традиций и обычаев, характерных для их празднования.

4 ноября - Аень народного единства, еще один праздник, который отмечается с 2005 г. и связан с событиями 1612 г., когда войско народного ополчения, созданное в Нижнем Новгороде для освобождения русских земель от польских интервентов, штурмом взяло Китай-город и изгнало их. Понятно, что нынешней молодежи этот праздник не близок и не понятен, как и большинству российского народа. Более четырехсот лет его никто не праздновал, предыдущие поколения не передавало никаких традиций, связанных с этим событием. Этот новый праздник пока очень трудно 
приживается, что подтверждается и данными исследования, проводимого в осенний период с 2007 г. Институтом психологии РАН. Результаты исследования показывают, что для большинства опрошенных это «выходной», так ответили $93 \%$; $60 \%$ отметили «непонятно что», 58\% считают его обычным днем, 56\% полагают, что это не праздник, 53\% рассматривают его как придуманный (навязанный) праздник, 51\% россиян введение его связывают с заменой праздника 7 ноября, 49\% называют его как день народного единства, 44\% - день освобождения Москвы и 43\% новое/нововведение (Борисова, 2017: 30). Анализ полученных ответов показывает, что за 15 лет существования он не стал для большинства праздником. В основном общество как помнило «красный день календаря» 7 ноября, так и сейчас помнит, ведь традицию праздновать 7 ноября наши деды передали нашим родителям, а родители - нам. Памятные воспоминания не могут быть продиктованы людям. Народ выбирает из безграничного количества прошлых событий те, которые кажутся наиболее важными для осмысления своей истории. Новый праздник был искусственно навязан, а если праздник не затрагивает душевных струн, то он остается для многих людей просто очередным выходным днем.

\section{ЗАКАЮЧЕНИЕ}

Проанализировав современные массовые праздники патриотической направленности, можно сделать вывод о том, что нам необходимо научиться относиться с пониманием и уважением к собственной истории, традициям, ценностям, используя в этих целях все формы воспитательного воздействия, в том числе и массовые праздники. Как показывает опыт, российские праздники патриотической направленности должны быть не формальными, а искренними, интересными и содержательными.

Массовым праздникам необходима государственная поддержка с четкой идеологией, направленной на воспитание чувства патриотизма у подрастающего поколения. Имеющиеся программы государства, в том числе «Патриотическое воспитание граждан Российской Федерации» (2011-2015, 2016-2020 гг.), обладают большим потенциалом, который еще недостаточно используется для решения задач по воспитанию патриотических чувств у российской молодежи. Надо максимально использовать различные выразительные средства и приемы эмоционального воздействия на людей и подрастающее поколение, чтобы воспитать у них чувство сопричастности заложенным в празднике идеям.

В прошлые культурно-исторические эпохи у праздников было разное наполнение, но ближе всего к нам советские праздники по их содержанию и временному отрезку. С некоторыми из них мы прожили определенное время. Но они были незаслуженно преданы забвению. Взамен обществу не предложили ничего интересного и содержательного. Нынешняя Россия нуждается в уважительном отношении к историческому и праздничному наследию. Массы людей, вовлеченные в праздничные мероприятия, должны четко осознавать, в чем они участвуют. Несоблюдение традиций и ритуалов, неграмотная встроенность их в праздничное торжество значительно снижают их результативность. Нынешнее время таково, что мы наблюдаем некое непонимание, неоцененную роль массового праздника для организации «высокого досуга» или «величайшего досуга».

Появляющиеся новые праздники, привнесенные из другой культурной среды (например, Хэллоуин, Аень святого Валентина, Аень святого Патрика и др.), возмещают неудовлетворение народных масс, особенно молодежи, содержанием, организацией 
и проведением скорее всего новых массовых российских праздников. Их желание продемонстрировать и ощутить дружеское единодушие в процессе общего праздника, который дает возможность освободиться от всех условностей и вызывает светлые радостные чувства.

Праздничная культура, которая в недалеком прошлом успешно развивалась и совершенствовалась, начинает постепенно теряться. И это ставит нас перед необходимостью обращения к праздничному культурному наследию, накопившемуся за долгую историю, где праздники были адекватны своей эпохе, тесно связаны с социальными и духовными идеалами. Праздник как важный инструмент воспитания, как бы он ни видоизменялся, должен соответствовать коду культуры.

\section{ПРИМЕЧАНИЯ}

1 Владимир Путин: «Мы должны строить свое будущее на прочном фундаменте» (2012) [Электронный ресурс]// Русская народная линия. 12 сентября. URL: http://ruskline.ru/news_rl/ 2012/09/13/vladimir_putin_my_dolzhny_stroit_svoyo_buduwee_na_prochnom_fundamente/ (дата обращения: 12.08.2019).

2 Устав полка [Электронный ресурс] // Бессмертный полк. URL: https://www.moypolk.ru/ ustav-polka (дата обращения: 12.08.2019).

\section{СПИСОК АИТЕРАТУРЫ}

Борисова, А. М. (2017) Коллективные проявления как психологический фактор интеграции в праздничной культуре // Вестник Московского государственного областного университета. Серия: Психологические науки. № 4. С. 30-37.

Генкин, А. М. (1975) О Араматургии и режиссуре массовых праздников. М. : Просвещение. 140 с.

Культурология. XX век (1998) : энциклопедия : в 2 т. / главный редактор, составитель и автор проекта С. Я. Аевит. СПб. : Университетская книга. Т. 2. 447 с.

Аата поступления: 04.09.2019 2.

\section{PATRIOTIC ORIENTATION OF MASS HOLIDAYS IN MODERN RUSSIA AND YOUTH}

G. P. KHORINA, D. A. StreltSova

MOSCOW UNIVERSITY FOR THE HUMANITIES

The article analyses the issue of patriotic orientation of mass holidays in modern Russia and its perception by Russia's youth.

The authors point out that the changes taking place in Russia's social development have led to a shift in some young people's attitude towards their country and its history. Unfortunately, the state does not pay enough attention to young people. In search of self-fulfillment they often come under the influence of people with an anti-Russian, antipatriotic mindset. In order to prevent this, it is necessary to use various forms of educational stimuli. Numerous patriotic events and holidays could play an important role here.

Keywords: holiday; mass holiday; patriotism; patriotic education; Russia; Victory Day; Russia Day; National Flag Day; National Unity Day

\section{REFERENCES}

Borisova, A. M. (2017) Kollektivnye proiavleniia kak psikhologicheskii faktor integratsii v prazdnichnoi kul'ture. Vestnik Moskovskogo gosudarstvennogo oblastnogo universiteta. Seriia: Psikbologicheskie nauki, no. 4, pp. 30-37.

Genkin, D. M. (1975) O Dramaturgii i rezhissure massovykh prazdnikov. Moscow, Prosveshchenie. $140 \mathrm{p}$. 
Kul'turologiia. XX vek (1998) : entsiklopediia : in 2 vol. / ed. by S. Ia. Levit. St. Petersburg, Universitetskaia kniga. Vol. 2. 447 p.

Submission date: 04.09.2019.

Хорина Галина Петровна - доктор философских наук, профессор, профессор кафедры истории и регионоведения Московского гуманитарного университета. Адрес: 111395, Россия, г. Москва, ул. Юности, д. 5. Тел.: +7 (499) 374-70-88. Эл. адрес: galhorina@mail.ru

Стрельцова Аарья Александровна - заведующая учебным кабинетом, преподаватель кафедры культуры и искусства Московского гуманитарного университета. Адрес: 111395, Россия, г. Москва, ул. Юности, д. 5. Тел.: + 7 (499) 374-59-40. Эл. адрес: dgorinova@mail.ru

Khorina Galina Petrovna, Doctor of Philosophy, Professor, Professor, Department of History and Regional Studies, Moscow University for the Humanities. Postal address: 5, Yunosti St., Moscow, Russian Federation, 111395. Tel.: +7 (499) 374-70-88. E-mail: galhorina@mail.ru

Streltsova Darya Aleksandrovna, Manager, Lecturer, Department of Culture and Art, Moscow University for the Humanities. Postal address: 5, Yunosti St., Moscow, Russian Federation, 111395. Tel.: +7 (499) 374-59-40. E-mail: dgorinova@mail.ru 